\title{
Packet method of data transmission in radar and radio navigation upper-air sounding systems
}

\author{
Oleg Plokhikh ${ }^{1}$, Andrey Gusev ${ }^{1, *}$, Sergey Kudinov ${ }^{1}$, and Nicolay Shirshov ${ }^{2}$ \\ ${ }^{1}$ Ural Federal University named after the first President of Russia B.N.Yeltsin, Ekaterinburg, 620002, \\ Russian Federation \\ ${ }^{2}$ FSUE "TsENKI", Shchepkin st. 42, Moscow, Russian Federation, 107996
}

\begin{abstract}
The use of the packet method of transmission of coordinatetelemetry information to the ground station in radiosondes of upper-air sounding systems can significantly reduce the influence of interference arising in the radio channel, increase the reliability of receiving transmitted information, reduce the cost of measurements of meteorological parameters of the atmosphere on the scale of the aerological network of the Russian Federation.
\end{abstract}

\section{Introduction}

Domestic radar-type SRs use the method of measuring the direction and range to calculate the coordinates, speed and direction of movement of the radiosonde in a free atmosphere.

Measurement of angular coordinates: azimuth $(\beta)$, elevation $(\varepsilon)$ is carried out by the method of conical scanning. A distinctive feature of domestic SRs is the measurement of the slant range $(\mathrm{Rn})$ by a radio-pulse method to an aerological radiosonde of the MRZ-3 type, equipped with a super-regenerative transceiver providing an active response signal at a distance of at least $250 \mathrm{~km} \mathrm{[1-4].}$

The experience in developing the navigation SR "Polyus" showed the advantages of transmitting telemetry information (TI) about meteorological parameters of the atmosphere (MPA) from the ARS to the base station in the form of digital packets [5 -7]. To improve the tactical and technical characteristics of the radar SR and to ensure the maximum compatibility of its MPA sounding data with the data received by the radio navigation SR "Polyus", it was necessary to modernize the radar SR by introducing the packet method of transmitting telemetry information (TI) from the ARS to the base radar [8, 9]. In order to improve the radar SR, a microprocessor radiosonde MRZ-3MK working in batch mode for transmitting telemetric information was developed and tested.

\section{Problem statement}

The traditional method of transmitting TI from the ARS is to transmit information about the MPA during one cycle, the duration of which is Tcyc $=20 \mathrm{~s}$ (Fig. 1), [1-4]. During this time interval, the ARS measuring generator for $5 \mathrm{~s}$ sequentially generates the frequency of the

\footnotetext{
*Corresponding author: a.v.gusev@urfu.ru
} 
reference (calibration) channel with a period of $\operatorname{Trc}=0.7 \mathrm{~ms}$, the frequency of the measuring channels of temperature $\mathrm{Tt}$ and humidity $\mathrm{Tu}$. For example, the period of the measuring generator when the temperature sensor is connected in the entire range of changes in the temperature of the medium from minus $90^{\circ} \mathrm{C}$ to plus $50^{\circ} \mathrm{C}$ varies within $\mathrm{Tt}=$ $0.8-60.0 \mathrm{~ms}$. The coding of TI is carried out by frequency-pulse manipulation (PFM) pulses of a measuring generator of a pulse repetition rate of radio pulses $(800 \mathrm{kHz})$ emitted by the SPP radiosonde. Reception of TI ARS, processing and formation of meteorological information is carried out in a ground-based radar by calculating meteorological parameters from the values of the received periods $\mathrm{Top}, \mathrm{Tt}$, $\mathrm{Tu}$, taking into account the known calibration coefficients of the ARS transmitter and sensors.

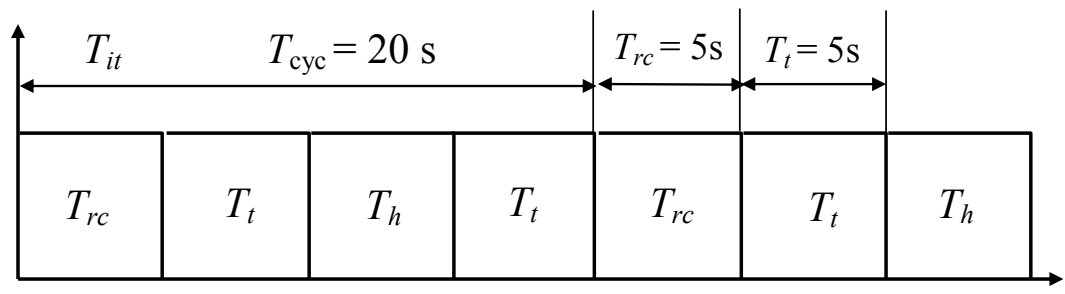

$t$

Fig. 1. Information frame structure.

In the considered transmission method, the following problems arise when receiving and processing telemetric information:

1. The long interval of time for obtaining meteorological information (Tcyc $=20 \mathrm{sec}$.) creates the problem of its stable reception during signal fading due to ARS swaying, since the signal fading interval at the output of the radar receiver is usually 1-3 sec. The appearance of at least one fading of the signal during the information transmission cycle does not allow to calculate the MPA and obtain the measurement result.

2. Another problem occurs when the frequency of telemetric signals caused by spurious amplitude modulation of the radiation of the ARS transmitter in the channel bandwidth of the angular automation radar, which leads to a violation of the stability of the automatic tracking ARS by angular coordinates.

3. The third problem is related to limiting the maximum value of the period of telemetric frequencies of the ARS measuring generator equal to Ti $\max =60.0 \mathrm{~ms}$.

This limitation does not allow the use of modern temperature sensors with a small time constant and high resistance (about 2-4 M $\Omega$ ) at low temperatures of the order of minus 80 $90^{\circ} \mathrm{C}$.

4. Additional difficulties arise when receiving a pulsed telemetric signal in the radar receiver when the period of the video pulses changes within a significant range of Ti max $=$ 0.7-60.0 ms, since their duty cycle and the constant component of the signal change tens of times, which complicates the operation of the threshold device of the period meter pulses.

Therefore, to improve the tactical and technical characteristics of a radar SR and to ensure maximum compatibility of its MPA sounding data with the data received by the radio navigation SR "Polyus", it is necessary to modernize the radar SR by introducing the packet method of transmitting telemetric information (TI) from the ARS to the base radar.

\section{Questions of the optimal reception of packet telemetry information theory in radar SR}

In order to substantiate the methods of optimal reception of digital ARS signal in radar SR and to elaborate technical recommendations for the development of on-Board and ground 
equipment, it is necessary to make some explanations regarding the signal transformations in the linear and digital parts of the radar receiver [10-15].

From the output antenna to the input low noise amplifier (LNA) the radar receives the realization of a random signal $y_{\text {in }}(t)$ represents the mixture of the transmitted binary signals $\mathrm{u}_{\mathrm{iin}}(\mathrm{t})$ in a sequence of radio pulses SPP to the carrier frequency and random interference $1680 \mathrm{MHz} \mathrm{n}_{\text {in }}(\mathrm{t})$

$$
\mathrm{y}_{\text {in }}(\mathrm{t})=\mathrm{u}_{\text {iin }}(\mathrm{t})+\mathrm{n}_{\text {in }}(\mathrm{t})
$$

Information about the MPA is transmitted in the form of a digital code by pulsefrequency manipulation (PFM) subcarrier SPP frequency. The Central value of the subcarrier frequency (radio pulse repetition frequency) of the SPP is $800 \mathrm{kHz}$. The deviation of the subcarrier frequency is within $\Delta \mathrm{f}= \pm 15 \mathrm{kHz}$. Then, by using a mixer and a heterodyne, the spectrum of radio pulses is transferred to the intermediate frequency of the radar receiver. After the amplitude detector, the video pulses with a frequency fs $=800 \pm 15$ $\mathrm{kHz}$ and a duration $\Delta \tau=0.25 \mu$ s enter the narrow-band intermediate-frequency amplifier, in which the first harmonic of the video pulse frequency is exarticulated. Next, a harmonic signal containing telemetry information in the form of PFM is fed to the input of the frequency detector (FD). From the FD output, a mixture of digital binary signal and interference $\mathrm{y}(\mathrm{t})$ is fed to the correlator and the threshold device made on the microcontroller MCU (Fig.2).

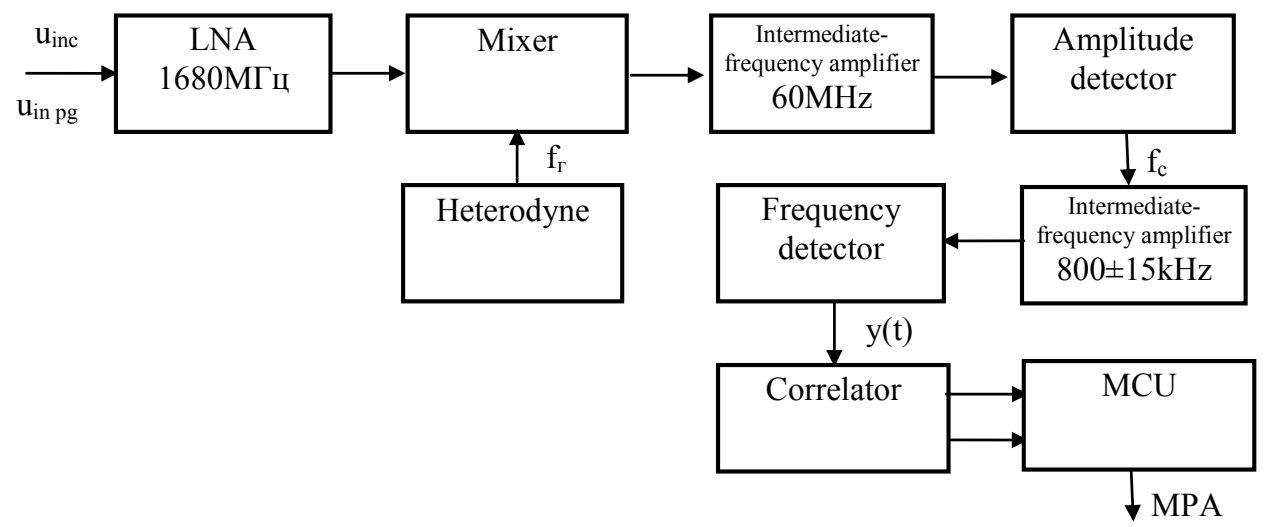

Fig. 2. Block diagram of the telemetry channel radar receiving device.

A generalized block diagram of the telemetry channel of the radar receiver is shown in Fig.2. In the process of optimal processing in the linear part of the receiver, the spectrum of the analog signal $y_{\text {in }}(t)$ is respectively converted and transferred to the intermediate frequency, then fed to the frequency detector (FD). As a result of transformations at the FD output signal $\mathrm{y}(\mathrm{t})$ is formed which is the sum of binary digital signals $\mathrm{u}_{\mathrm{i}}(\mathrm{t})$ and random interference $n(t)$.

$$
y(t)=u_{i}(t)+n(t) .
$$

At the FD output of the radar receiver, a multipolar digital binary signal of the MPA code sequence is formed. Next, this signal is converted into $\mathrm{y}^{k}(\mathrm{t})$ - digital sequence of a unipolar binary video pulses code of MPA sequence and enters the input of the correlator, Fig.3. In accordance with the designations adopted in Fig.7 the main parameters of the signals have the following physical meaning: $\mathrm{u}^{\mathrm{k}} 1(\mathrm{t})$ - symbol 1 signal; $\mathrm{u}^{\mathrm{k}} 0(\mathrm{t})$ signal of symbol $0 ; \tau^{\mathrm{k}} 1$ - the duration of a symbol 1 signal; $\tau^{\mathrm{k}} 0$ signal duration of symbol 0 ; $\tau_{\mathrm{ti}}=\tau^{\mathrm{k}} 1+\tau^{\mathrm{k}} 0$ the duration of the digital stream clock pulses period (practically $\tau^{\mathrm{k}} 1=\tau^{\mathrm{k}} 0$ ). 
The theoretical features of receiving telemetry information in the form of this digital stream are reduced to the Bayesian problem of statistical character recognition of binary code. After receiving the $y^{k}(t)$ signal, hypotheses can be made about which of the $u_{i}^{k}(t)$ flow signals was received: 0 or 1 . This problem is related to binary code character recognition, so it belongs to the binary class problems associated with the detection of signals with known parameters, which is typical for digital communication systems with synchronization [16]. Next, we consider the case of transmission of MPA characters by binary code with "active zero", because of the PFM subcarrier frequency, energy of these signals is the same. The symbols 1 are transmitted by signal $\mathrm{u}^{\mathrm{k}}{ }_{1}(\mathrm{t})$, the symbols 0 are transmitted by signal $\mathrm{u}_{0}^{\mathrm{k}}(\mathrm{t})$, Fig. 3 .

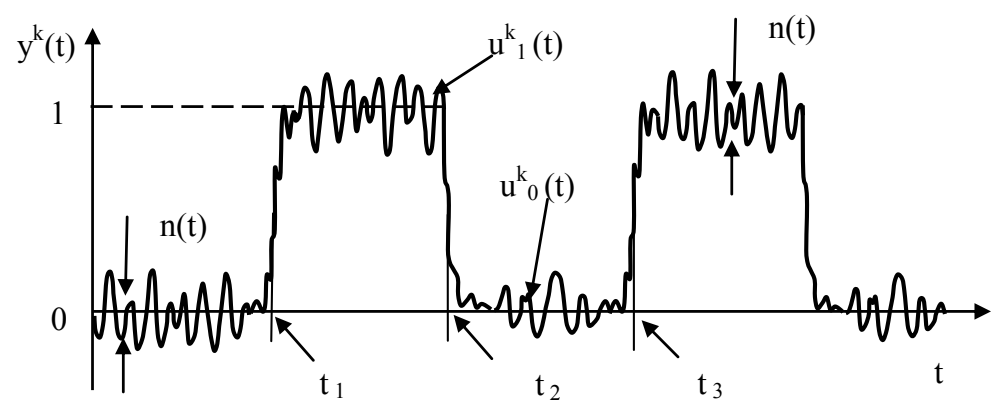

Fig. 3. Basic parameters of the digital signal at the input of the decision-making device.

Erroneous decisions of the k-th digit symbol receiving of the code sequence can be either in receiving 1 when 0 was transmitted, or in receiving 0 when 1 was transmitted.

In the considering problem the cost of losses at erroneous reception of symbols of the $\mathrm{k}$-th digit can be accepted identical $\mathrm{C}_{10}{ }^{(\mathrm{k})}=\mathrm{C}_{01}{ }^{(\mathrm{k})}$ as it leads to the omission of information about symbol. If the symbol is received correctly, the losses are zero. Further, it is assumed that the $\zeta_{\mathrm{j}}$, which is transmitted by MPA digital code, takes any value within the physical feasibility of 0 to $\zeta_{\mathrm{j} \max }$. In this case, the a priori transmission probabilities in each of the digits of the symbols 0 and 1 are highly likely to be statistically the same: $\mathrm{P}_{0}{ }^{(\mathrm{k})}=\mathrm{P}_{1}{ }^{(\mathrm{k})}=0.5$.

When solving the binary problem of detecting the digital code symbol, one of four outcomes is possible:

1. The hypothesis of absence of a signal $\mathrm{H}_{0}$ is accepted and the hypothesis $\mathrm{H}_{0}$ is true;

2. The hypothesis of signal reception $\mathrm{H}_{1}$ is accepted and the hypothesis $\mathrm{H}_{1}$ is true;

3. The hypothesis of absence of a signal $\mathrm{H}_{1}$ is accepted and the hypothesis $\mathrm{H}_{0}$ is true;

4. The hypothesis of signal reception $\mathrm{H}_{0}$ is accepted and the hypothesis $\mathrm{H}_{1}$ is true.

At introduction the densities of conditional probabilities $\mathrm{p}\left(\mathrm{y} \mid \mathrm{u}_{0}\right)$ and $\mathrm{p}\left(\mathrm{y} \mid \mathrm{u}_{1}\right)$ realization of $y(t)$, provided that the signals $\mathrm{u}_{0}$ and $\mathrm{u}_{1}$ were transmitted respectively, it is possible to use the ratio of these conditional probability densities as a one-dimensional random variable to develop the optimality criterion.

$$
\Lambda(\mathrm{y})=\mathrm{p}\left(\mathrm{y} \mid \mathrm{u}_{1}\right) / \mathrm{p}\left(\mathrm{y} \mid \mathrm{u}_{0}\right)
$$

Type of functions of conditional densities of signal distribution y $(\mathrm{t})$ of digital symbols of transfer 0 and 1 according to Fig.3 is shown in Fig.4. The relation (3) is called the likelihood relation. Thus, in the Bayesian interpretation, the optimality criterion for detecting the information symbol is reduced to determining the threshold ratio.

$$
\Lambda(\mathrm{y})>\eta \text { when } \mathrm{H}_{1} \text {, or } \Lambda(\mathrm{y})<\eta \text { when } \mathrm{H}_{0},
$$

where $\eta$ is the threshold ratio of probabilities chosen from the cost of right and wrong decisions. 
The threshold voltage $u_{p}$ is determined according to the criterion of optimality $\eta$ for a particular technical design of the decision-making device.

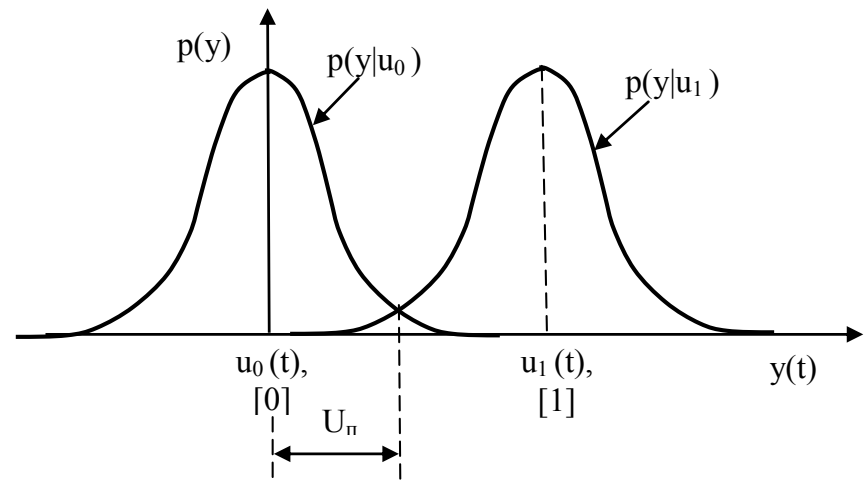

Fig. 4. The form of conditional densities functions of $y(t)$ signal distribution of transfer 0 and 1 digital symbols.

Often in practice, instead of (8) use the ratio of logarithms of likelihood ratio $\ln \Lambda(y)$ and the optimality criterion $\ln \eta$. In this case, the probability of reception in each of the digits of the characters 0 and 1 are assumed to be equal: $\eta=1$, and $\ln \eta=0$. Therefore, the criterion of optimal detection of a symbol of any digit on the background of white noise takes the form:

$$
\sum_{k=1}^{m}\left\{\left[\mathrm{y}\left(\mathrm{t}_{\mathrm{k}}\right)-u_{0}\left(t_{k}\right)\right]^{2}-\left[y\left(t_{k}\right)-u_{1}\left(t_{k}\right)\right]^{2}\right\} \Delta t \underset{\leq}{\geq} 0 .
$$

In the case of deterministic signals $\mathrm{u}_{\mathrm{i}}(\mathrm{t})$ and interference $\mathrm{n}(\mathrm{t})$, representing normal white noise, bounded by the frequency band $\Delta \mathrm{f}$ Bayes criterion for deciding on the choice of a hypothesis for a known implementation of the received signal y $(\mathrm{t})$ can be presented in general form

$$
-\frac{1}{N_{0}} \int_{0}^{T}\left\{\left[y(\mathrm{t})-\mathrm{u}_{1}(\mathrm{t})\right]^{2}-\left[\mathrm{y}(\mathrm{t})-\mathrm{u}_{0}(\mathrm{t})\right]^{2}\right\} d t \stackrel{\leq}{\geq} \ln \eta
$$

where $\mathrm{N}_{0}$ is the noise spectral power; $\eta$ is the threshold ratio of conditional probability densities (4).

As mentioned earlier, the radar SR under consideration uses pulse-frequency manipulation (PFM) of the subcarrier frequency $f$ with the SPP to transmit digital information, i.e. a binary code with "active zero" is used [16]. In particular, the transmission of 1 uses a signal $\mathrm{u}_{1}(\mathrm{t})$ which is proportional to the frequency $\mathrm{f}_{\mathrm{s}}=813 \mathrm{kHz}$, and the transmission of 0 uses a signal $\mathrm{u}_{0}(\mathrm{t})$ which is proportional to the frequency $\mathrm{f}_{\mathrm{s}}=787 \mathrm{kHz}$. Both signals have the same energy $\mathrm{E}$ and duration $\tau_{\mathrm{i} 1}=\tau_{\mathrm{t} 0}$ :

$$
\left.\int_{0}^{T} u_{1}^{2}(\mathrm{t})\right]^{2} d t=\int_{0}^{T} u_{0}^{2}(t) d t=E
$$

The signal-to-noise ratios for $\mathrm{u}_{1}(\mathrm{t})$ and $\mathrm{u}_{0}(\mathrm{t})$ at the input of the correlation device will be the same. In this case, the optimality criterion can be represented as a correlation integral: 


$$
\int_{0}^{T} y(t) u_{1}(\mathrm{t}) d t \leq / \geq \int_{0}^{T} y(t) u_{0}(t) d(t)
$$

The meaning of relation (8) is that the decision is made in favor of the symbol for which the correlation integral takes a greater value (Fig.5).

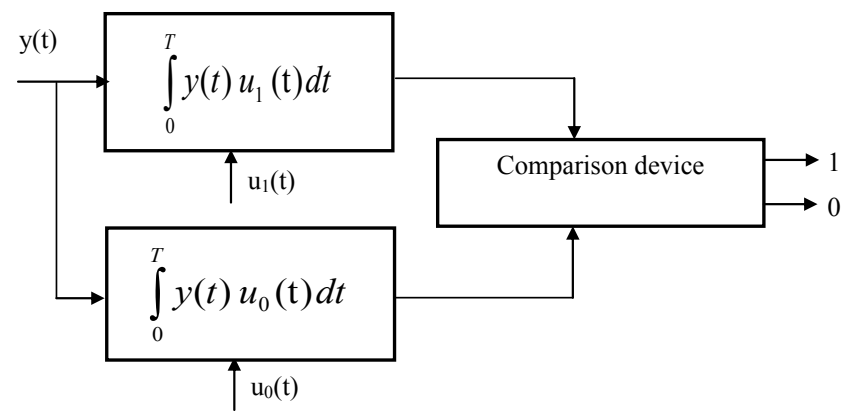

Fig. 5. Block diagram of correlation decision-making device.

The considered approach for determining the methods of processing the information signal in the radar receiver provides the highest probability of correct detection of the symbols of the entire transmitted digital packet and, ultimately, the correct definition of the MPA. Calculation of correlation functions of signals $u_{1}(t)$ and $u_{0}(t)$ is carried out in the microcontroller of the radar receiver.

The Fig. 6 shows for comparison the graphs of the theoretical dependences of the probability of error $\mathrm{P}_{\text {osh }}$ when receiving a single character from the ratio of signal power to interference power $\mathrm{q}^{2}=\mathrm{P}_{\mathrm{s}} / \mathrm{P}_{\mathrm{i}}$ for three types of modulation: PAM, PFM, and PPM, calculated using the expression:

$$
P_{o u}=1-\frac{1}{\sqrt{2 \pi}} \int_{-\infty}^{g} \exp \left(-0,5 u^{2}(t) d t\right.
$$

where $g=\sqrt{0,5 q}$ for PAM; $g=\sqrt{q}$ for PFM; $g=\sqrt{2 q}$ for PPM.

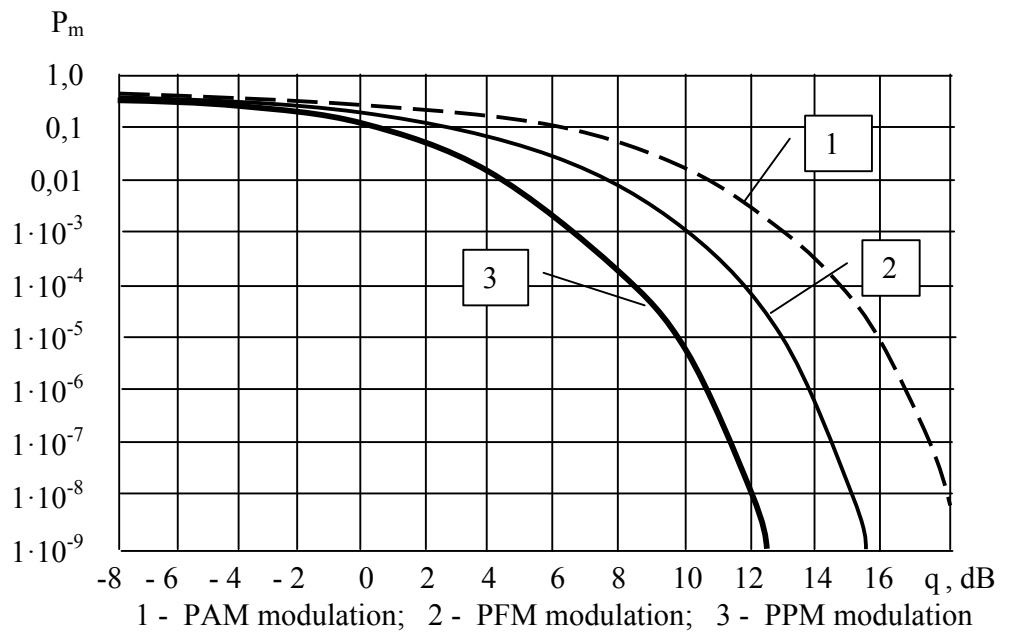

Fig. 6. The dependence of the error probability $\mathrm{P}$ in the reception of a single character on the ratio of the signal power to the noise power q for modulation type PAM, РFМ и РРМ. 
The minimum calculated signal-to-noise ratio $\mathrm{q}=\mathrm{y}(\mathrm{t}) / \mathrm{n}(\mathrm{t})$ in the telemetry channel in the design of radar SR is assumed to be $\mathrm{q}=3$, which corresponds to the signal-to-noise ratio $\mathrm{q}^{2}=\mathrm{P}_{\mathrm{s}} / \mathrm{P}_{\mathrm{i}}$ equal to $10 \mathrm{~dB}$. Further, it is assumed that the signal spectrum is consistent with the bandwidth of the receiver. The probability of error for receiving information of an elementary character is: to PAM $\mathrm{P}_{\mathrm{m}}=10^{-2}$, for the FIM $\mathrm{P}_{\mathrm{m}}=10^{-3}$, for PIM $\mathrm{P}_{\mathrm{m}}=10^{-5}$. It should be emphasized that the use of PFM can significantly reduce the probability of error (less than $\mathrm{P}_{\mathrm{m}}=10^{-5}$ ), but it requires appropriate modernization of the radiosonde and radar equipment.

Because of during the observation of one information cycle $\mathrm{T}_{\mathrm{C}}=2 \mathrm{sec} .20$ packets are transmitted, then the correlation processing of all packets with coherent signal energy storage theoretically leads to an increase in the signal-to-noise ratio $\mathrm{q}$ in the telemetry channel by about 20 times, which corresponds to an increase of q by $13 \mathrm{~dB}$. When using the incoherent accumulation method, the signal-to-noise ratio $\mathrm{q}$ increases by $6.5 \mathrm{~dB}$. In accordance with the graph shown in Fig. 6, the probability of error in the optimal processing of all packets during the information cycle for the PIM method is reduced to less than $\mathrm{P}_{\mathrm{m} \mathrm{k}}=10^{-9}$. These theoretical results are confirmed by the field tests data [14].

Further, it should be noted that in the considered conditions of receiving telemetry information, considering the ratio (11), technically the simplest criterion for optimal reception of the information symbol 0 or 1 can serve as a threshold voltage $\eta=U p$ determined by the ratio

$$
\eta=U_{\Pi}=0,5\left\{\int_{-\infty}^{\infty} p\left(y \mid u_{1}\right) d t-\int_{-\infty}^{\infty} p\left(y \mid u_{0}\right) d t\right\},
$$

On the basis of the above theoretical provisions in [11] developed the structure of the full digital transmission code MPA. The article also discusses the structure of the protocol and the tests results of the modernized radiosonde system (SR) of the atmosphere of the radar "Vector-M" together with MRZ-3MK operating in the batch mode of telemetry information transmission.

\section{Development of a digital telemetry information transmission method from the side of the radiosonde to SR radar}

On the basis of the results obtained in the development of the navigation SR "Polyus", technical means were developed and modernization of the radar SR was carried out by integration of a packet method of telemetry information transmission from the ARS to the base radar [11-14]. These works examines features of the development of the microprocessor type of radiosonde MRZ-3MK, Protocol settings digital packet telemetry data transmission. Features of the packet method of forming telemetry information in the ARS type MRZ-3MK are as follows.

The block diagram of the ARS is shown in Fig. 7. The composition of the aerological radiosonde ARS includes: primary unit (sensors) and secondary (measuring) converters MPA, electronic control unit, microcontroller (MCU), on which the device pairing, a packet telemetry information computer and shaper (PTI), and modulating voltage of the microwave module SPP shaper and frequency modulator are based.

The implementation of ARS on a universal microcontroller (based on the Cotrex-M3 core with a $100 \mathrm{MHz}$ working clock frequency) allows hardware and software to solve the following tasks:

- forms the main time cycle of the ARS;

- controls the operation of the secondary measurement converter and measures the time parameters of the signals at its output; 


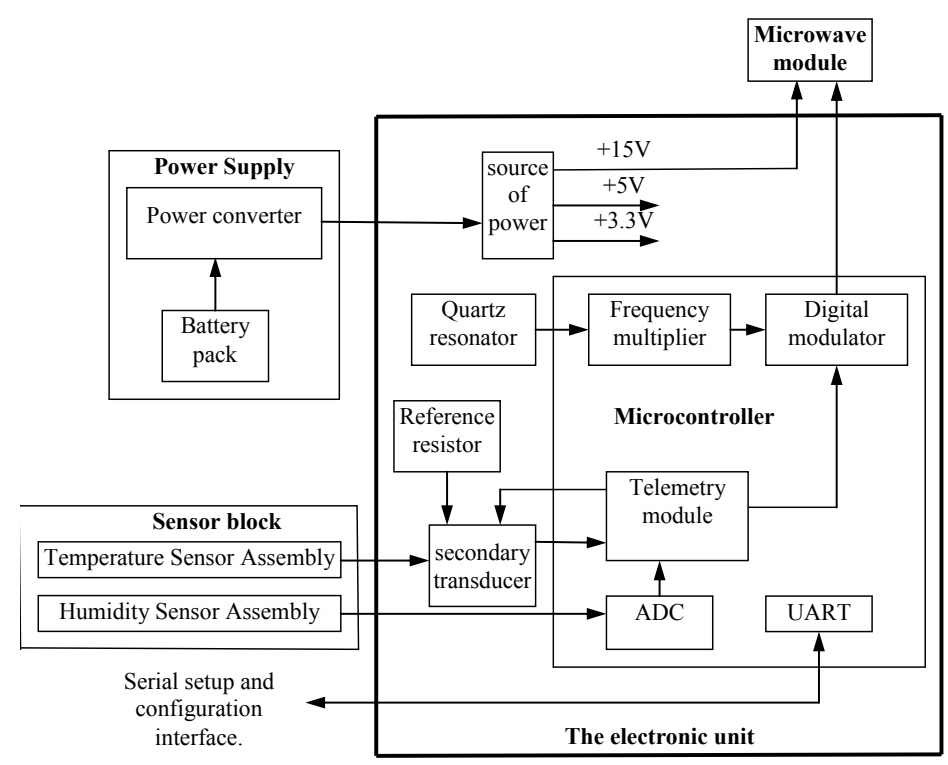

Fig. 7. Block diagram of ARS MRZ-3MK.

- measures the output voltage of analog sensors (humidity sensor);

- provides formation, coding and transmission of information package containing calculated and measured values of MPA, as well as parameters of the current operating mode;

- supports ARS pre-flight preparation mode.

Because the information frequency band of telemetry information MPA does not exceed $\Delta \mathrm{F}<0.5 \mathrm{~Hz}$ [8-10], its update is required to be implemented at a rate of at least once every two seconds. The period of the information stream clock pulses $\tau_{\mathrm{ti}}$ is selected in accordance with a given bandwidth telemetry channel radar $\Delta \mathrm{f}=5.0 \mathrm{kHz}$ and a spectral width of digital pulses:

$$
\tau_{\mathrm{ti}}=2 / 5,0=0,420 \mathrm{~ms}
$$

The volume of the information packet is 240 bytes. The duration of the fragment of the information package containing all the information about the MPA is

$$
\mathrm{T}_{\mathrm{P}}=0.42 \mathrm{~ms} \times 240 \text { bytes }=100 \mathrm{~ms} \text {. }
$$

Redundancy implemented into the structure of the information packet allows to correct individual bit errors that may occur due to interference, and repeatedly duplicate packets to deal with freezing of the signal. The information rate of data transmission in the telemetry channel is 1200 baud. The method of encoding information bits in a packet is a selfsynchronizing code of the Manchester 2 type.

Measurement of meteorological parameters of the atmosphere in ARS proceeds as follows: MPA affect the sensors unit and secondary transducers of ARS, whose output signals in the form of video pulses measuring periods are fed to the input of MCU telemetry module. Information about the reference channel measuring periods, temperature and humidity in the form of a digital code is supplied to the computing device and the packet telemetry information generator (PTI). In MCU processor within $T_{P}=100 \mathrm{~ms}$. a digital packet containing 240 bytes of telemetry information received from ARS sensors is formed. Transmission of MPA in the form of digital packets is performed in simplex mode via radio channel from the radiosonde to the base radar. The transmission time of one packet of 
meteorological information is Tcyc $=100 \mathrm{msec}$. This ensures multiple transmission of packets during one cycle with variability of information at least 1 time in 2 seconds, which significantly increases the reliability of telemetry data reception in the conditions of fading of the radiosonde signal.

The physical speed of data transmission in the channel is $2400 \mathrm{bit} / \mathrm{s}$. The structure of one of the variants of the information package transmitted by ARS is shown in Fig. 8 . The total packet length is 30 bytes $\times 8=240$ bytes. For a 2400 bps transmission rate, this means that in 2 seconds 20 identical packets are transmitted. This redundancy allows, in the simplest case, to do without noise-proof encoding of the digital stream. Error bit recovery is performed by correlating multiple adjacent packets.

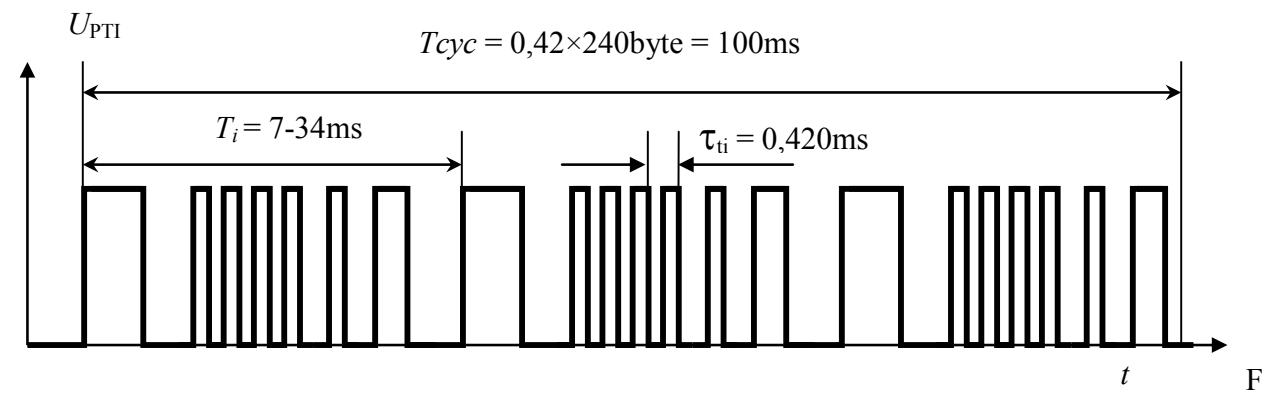

Fig. 8. A fragment of the information packet.

The ARS radio signal is optimally processed in the telemetry channel of the radar receiver. To decrypt telemetry data packets, the radar was modernized by implementation of a special subprogram that is part of the radar system software.

In general, the use of packet transmission of telemetry information in radar SR allows:

1. Reduce the duration of the information transfer cycle to 1-2 seconds., thereby to increase reliability of reception of telemetric information in the conditions of strong fading of ARS signal and to define in more detail a vertical profile of MPA;

2. Reduce the level of parasitic amplitude modulation (PAM) of the ARS signal due to the homogeneous nature of the PTI and increase the stability of the automatic tracking of the ARS by angular coordinates;

3. Remove restrictions from the duration of the ARS transducer periods and expand the possibility of using different types of MPA sensors;

4. Due to the small duty cycle of information pulses, it is essential to simplify the conditions for receiving and processing the signal in the radar receiver, thereby increasing the reliability of receiving telemetry information.

In the modernization process of the radar MARL-A and "Vector-M" by modification of the software to decode the packet information and the transmitting of MPA, testing shows that the performance of domestic radar MARL-A and "Vector-M" included in the SR significantly increases.

During 2013-2014 years in Central Aerological Observatory (CAO) of Roshydromet (Dolgoprudny) performed flight tests ARS MRZ-3MK with serial radar MARL-A, "VectorM" which are equipped with improved software [15]. According to test results the decision was made to start mass production of ARS MRZ-3MK for the aerological network of Roshydromet, the Eastern and Baikonur cosmodrome.

\section{Conclusion}

Theoretical analysis of optimum reception of telemetric information conditions about MPA from ARS Board to ground radar in the batch mode was performed. 
The description of the improved radiosonde MRZ-3MK which implements a packet method of telemetric information transfer is presented.

The results of research and experimental launches shows that the modernization of serial ARVC MARL-A, "Vector-M" ,that provides work with the ARS MRZ-3MK comes down to the modification of the software of telemetry radar blocks for decoding of receiving digital meteorological information packets.

To improve the reliability of meteorological information in the SR should be considered a promising application of FIM for the transmission of telemetry information and coherent energy storage of the information signal in the radar receiver.

\section{References}

1. Zaitseva N.A. Aerology - Gidrometeoizdat, 325 p. (In Russian) (1990)

2. Efimov A.A. The principles of operation of the aerological information and computer complex AVK-1. M .: Gidrometeoizdat, 149 p. (In Russian) (1989)

3. Ermakov V.I., Kuzenkov A.F., Yurmanov V.A. Atmospheric sounding systems. L.: Gidrometizdat, 304 p. (In Russian) (1977)

4. Ivanov V.E., Fridzon M.B., Essyak S.P. Radio sounding of the atmosphere. Technical and metrological aspects of the development and use of radiosonde measuring instruments / Under the general editorship of V.E. Ivanova. Ekaterinburg. UB RAS. 596 p. (In Russian) (2004)

5. Sterlyadkin V.V., Gorelik A.G., Shchukin G.G. Obzor metodov i sredstv vetrovogo zondirovaniya atmosfery // Problemy distancionnogo zondirovaniya, rasprostraneniya i difrakcii radiovoln: III Vserossijskie Armandovskie chteniya: Molodezhnaya shkola. Murom, pp. 24-42. (In Russian) (2013)

6. Shirshov N.V., Lamzin P.A., Plokhikh O.V., Gusev A.V., Chernykh O.A., Kudinov S.I., Ivanov V.E. The system of aerological radio sounding of the atmosphere of the Vostochny Cosmodrome / Proceedings of the III All-Russian Scientific Conference "Problems of Military-Applied Geophysics and Environmental Monitoring" // Under the general editorship of M. Penkov; - SPb .: VKA them. A.F. Mozhaysky, v. 2. p. 192-197 (2014)

7. N.V. Shirshov, S.A. Kurtashkin, V.E. Ivanov, O.V. Plokhikh, O.A. Chernyih. Test results of the navigation system for atmospheric radiosounding "Pole" at the Baikonur training ground // Proceedings of the II All-Russian Scientific Conference "Problems of Military-Applied Geophysics and Environmental Monitoring" / under the general. ed. S.S. Suvorov. - SPb .: VKA named after A.F. Mozhaysky, v. 1. - 432 p., P. 269-275 (2012)

8. Shirshov N.V., Plokhikh O.V., Gusev A.V., Kudinov S.I., Ivanov V.E., Rysev V.V. Packet transmission of telemetry data in atmospheric radar sensing radar systems. / Proceedings of the III All-Russian Scientific Conference "Problems of MilitaryApplied Geophysics and Environmental Monitoring" // Under the general editorship of M. Penkov; - SPb .: VKA them. A.F. Mozhaysky, v. 2. P. 184-191 (2014)

9. Gusev, A.V., Ivanov, V.E., Kudinov, S.I., Shirshov, N.V., Rysev, V.V.// Packet method of telemetry data transmission in the upper-air sounding system. CriMiCo 23rd International Crimean Conference Microwave and Telecommunication Technology, Conference Proceedings 6652643, pp. 1028-1029 (2013)

10. Digital communication. Theoretical foundations and practical application. Ed. 2 nd, rev.: Per. from English - M.: Williams Publishing House, 1104 p.: ISBN 5-8459-0497-8 (In Russian) (2003) 
11. Information technology in radio engineering systems: a training manual / V.A. Vasin, I.V. Vlasov, Yu.M. Egorov and others; under. ed. I.B. Fedorova M .: Publishing house of MGTU im. N.E. Bauman, 672 p. (2003)

12. Reference for radar. Ed. M. Skolnik. New York, 1970. Transl. From English. (in four volumes) under the general editorship of K.N. Trofimov. Volume 1. Basics of radar. Ed. J.S. Yitzhoki. M., "Soviet Radio", 456 p. (1976)

13. Tikhonov V.I. Statistical radio engineering. - M.: Soviet Radio, 680 p. (1966)

14. Digital communication. Theoretical foundations and practical application / Bernard Sklyar // Ed. 2nd, rev.: M.: Williams Publishing House, 1104 p. ISBN 5-8459-0497-8 (In Russian) (2003)

15. Plokhikh O.V., Gusev A.V., Kudinov S.I. [Modeling of a digital radio channel of the navigational upper-air sounding system] 27th Int. Crimean Conf. "Microwave \& Telecommunication Technology" (CriMiCo'2017). Sevastopol, vol. 7, pp. 1548-1554. (In Russian) (2017) 